more frequently pyrexial; but here also the fever is slight and transient, except where the process leads to bronchopneumonia. When therefore you find associated with the physical signs of general bronchitis more or less persistent elevation of the bodily temperature-a temperature which, although perhaps normal in the morning, keeps higher than natural in the afternoon or evening for several days, - you may be sure that you are dealing with something more than a simple bronchial catarrh, and, excluding the acute specific diseases, bronchial catarrh and pyrexia thus associated usually mean phthisis.

The other class of cases in which the thermometer is an important help in diagnosis is where the symptoms and physical signs are in themselves not sufficiently pronounced to enable us to speak certainly as to the nature of the illness. Physical signs are, perhaps, entirely wanting, but some lung symptoms associated with loss of flesh make us fear phthisis. Under such circumstances the existence of more or less persistent pyrexia indicates with tolerable certainty the phtnisical origin of the symptoms. The pyrexia, indeed, may in some cases precede for some weeks all reliable physical signs. Although the presence of fever under these and similar circumstances indicates the existence of phthisis, we must be careful how we at once conclude from its absence that there is no phthisical disease. The case should be carefully watched, and some time allowed to elapse before expressing a decided opinion. In using the thermometer as an aid to diagnosis in phthisis it is important to extend our observations over some aays, and not to draw conclusions from single records of the temperature; also to remember that phthisical pyrexia is of ten remittent, or even intermittent, in its type, the morning temperature being frequently normal, and the rise occurring in the afternoon or evening.

We have thus reviewed the nature of the evidence upon which may be based the diagnosis of phthisis. We have seen that in the large majority of cases this diagnosis rests upon the existence of abnormal physical signs; but that in some, where such signs are equivocal or absent, phthisis may be diagnosed with tolerable crrtainty from the association of such symptoms, more especially as hremoptysis, loss of flesh, and pyrexia. In all cases in which an opinion is based upon symptoms alone, the development of physical signs of phthisical disease will of course be anxiously looked for to confirm or negative our diagnosis.

THE

\section{RESULTS OF AMPUTATIONS PERFORMED IN THE GLASGOW ROYAL INFIRMARY DURING EIGHT YEARS ENDING DECEMBER 31sT, 1881.}

By M. THOMAS, M.D. ST. AND, \&c., SUPERINTENDENT, ROYAL INFIRMARY, GLASGOW.

IN the April number of the Glasgow Medical Joumal for 1877 I published a paper giving the statistics of amputations performed in the Glasgow Royal Infirmary for the twentytive years ending December 31st, 1873. The number was 1412 , the deaths 452 , giving a mortality of 32 per cent., a decrease of 4 per cent. as compared with the rate given by Dr. Lawrie, the immediate predecessor of Professor Lister in the chair of Surgery in the University of Glasgow and one of the surgeons to the hospital, and of 10 per cent. from the rate given by Dr. Steele, one of my predecessors, and now of Guy's Hospital. I now propose to continue these statistics for the eight years that have elapsed to December 31st, 1881 . In that short period 726 amputations have been performed, or rather more than half of the number which took place in the previous twenty-five years. The number of deaths was 166 , giving a mortality of 22.8 per cent., a reduction of 10 per cent. from my previous statistics, and a result which encourages the hope that the mortality after amputations may be still further diminished. Classifying amputations, as in my previous paper, under the three divisions of primary and secondary after injury, and for d'sease, I will under each of these headings specify the nature of the amputations, the total number of each, the number of d aths, and the mortality per cent. Before doing so I may state that the number of surgical beds is 318 , and that 21,220 =urgical patients have been treated to a conclusion duriug the eight years under consideration.

Primary amputations. - The number of these was 307 ; the deaths 98 , or $32 \cdot 3$ per cent., agdinst 659 ia twenty-five years, with a mortality of 36.5 per cent., a decrease of $4 \cdot 2$ per cent.

Shoulder-joint... 36 cases ... 13 deaths, or 36.1 asst 393 p.c. Arm ............6 $68 \quad, \ldots 14 \quad, \quad 20.5 \quad, \quad 33.5$,

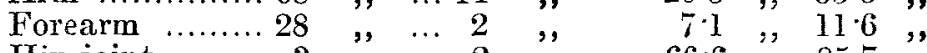
Hip-joint ....... $3 \quad, \quad \ldots \quad 2 \quad, \quad 66.6 \quad, \quad 857$

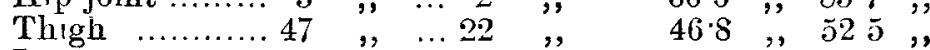

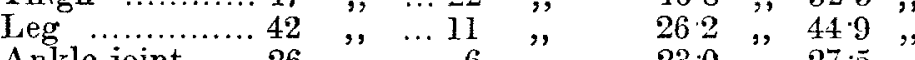
Ankle-joint ..... $26,2, \ldots 60,230,275$

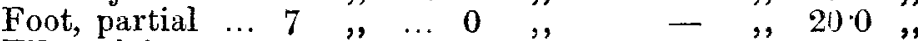
Elbow-joint...... 1 " " Knee-joint $\ldots \ldots 25,, \quad \ldots 13 \quad, \quad 52.0 \quad, \quad 400$ Multiple ....... 24 ", $\ldots 16 \quad, \quad 66.6 \quad, \quad 57 \cdot 0$,

Total.... $307, \quad \ldots \overline{99},, \quad \overline{37 \cdot 3}, \overline{36 \cdot 5}$,

I have not included amongst these 4 amputations at the wrist-joint, with one death, or 18 of the hand, without a death. The multiple amputations consist of $I$ through both knee-joints, resulting in death; 2 of arm and les, fatal 6 of both legs, with 5 deaths ; 1 of both feet, fatal; 4 of both thighs, with 3 deaths; 1 of leg, foot, and arm, recovered; 2 of shoulder and leg, 1 fatal; 3 of thigh and leo, 2 fatal 1 of knee and leg, with 1 death; 1 of foot and leg, recovered; and 2 of both forearms, recovered. These were all the result of formidable injuries, and indicate the nature of the others operated on.

The mortality of the four primary major operations, which are usually referred to as the test of success, was as follows:

Arm ........... 68 cases ... 14 deaths, or 20.5 agst. 33.5 p.c. Forearm ........ 28 ". ... 2 ", $7 \cdot 1$ " 11.6 ,

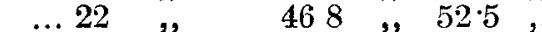
Leg ..............42 ", $\ldots 11 \quad$ ", $\quad 26.2 \quad, \quad 449$ ", Total.... $\overline{185},, \quad \ldots \overline{49},, \quad \overline{26 \cdot 4}, \overline{35 \cdot 8}$,

A decrease of 9.4 per cent. $\mathrm{Mr}$. Burdett, in his paper on the "Relative Mortality of Large and Small Hospitals," gives the mortality of these amputations in cottage hospitals as 20.9 per cent. This hospital is rapidly approaching these cottage hospitals in point of success, aud would, I have no doubt, surpass them if the cases were able to be compared.

Secondary amputation after injury. - The number of these during the eight years was 81 , with 27 deaths, or a mortality of $33 \cdot 3$ per cent., agdinst $51 \cdot 7$ previously, a decrease of 18.4 per cent. All cases operated on forty-eight hours after the injuries were received are put down in this and my previous paper, and in my annual reports under the heading of Secondary Amputations. Their nature was as follows :-

\begin{tabular}{|c|c|c|c|c|c|c|c|c|c|}
\hline Shoulder-joint... & & cases & 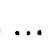 & & eath, & or & gst & & o.c \\
\hline ............... & 9 & $"$ & .. & 4 & ," & $44 \cdot 4$ & , & $31 \cdot 8$ & \\
\hline Forearm & 8 &, & $\ldots$ & 4 & ", & 500 &, & 289 & \\
\hline 'Thigh & 23 & $"$ & $\cdots$ & 9 & $"$, & $39 \cdot 1$ & $"$ & $76 \cdot 1$ & \\
\hline Leg & 17 & $"$, & $\cdots$ & 6 & , & $35 \cdot 3$ & , & $58 \cdot 0$ & \\
\hline Ankle-joint & 8 & ", & $\cdots$ & 0 & $"$ & - & $"$ & - & \\
\hline Foot, partial & 2 & $"$ & $\cdots$ & 0 & ", & - & ," & 235 & \\
\hline Knee-joint & 8 & " & $\cdots$ & 3 & $"$ & $37 \cdot 5$ & ," & $100^{\circ} 0$ & \\
\hline Both legs & 1 & $"$ & $\cdots$ & 0 & $" n$ & - & "' & 1000 & 1 \\
\hline ta & & 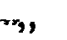 & & 2 & & $33 \cdot 3$ & & 7 & \\
\hline
\end{tabular}

Mortality of the Four Secondary Major Amputations.

Arm $\quad \ldots \quad \ldots \quad 9$ cases ... 4 deaths, or 44.4 agst. 31.8 p.c. Forearm ........ 8 8 $, \ldots .4 \quad, \quad 50.0$, $28 \cdot 9$,

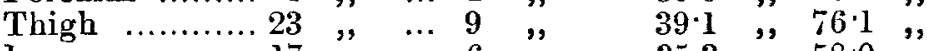
Leg ............ $17, \ldots 6 \quad, \quad 353 \quad, \quad 580$, Total ..... $\overline{57}, \quad \overline{23},, \quad \overline{40.3}, \overline{54.8}$,

A decrease of 145 per cent. on previous results.

Amputations for Disecse.-The number of these was 338 , the deaths 40 , the mortality $11 \cdot 8$, ag ainst $21 \cdot 9$, a decrease of 
$10 \cdot 1$ per cent. During the previous twenty-five years the number operated on under this class was 583 .

\section{Nature of the Amputation.}

Shoulder-joint. 6 cases ... 1 death, or 16.6 agst. 33.3 p.c.

\begin{tabular}{|c|c|c|c|c|c|c|c|}
\hline $\mathrm{rm}$ & $2 ?$ & & & & 0.0 & 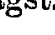 & 000 \\
\hline Forearm & 13 & $"$ & & & 7.7 & & \\
\hline Hip-joint & $\begin{array}{r}10 \\
4\end{array}$ & $"$ & $=\cdots$ & "' & 50.0 & $"$ & 4.7 \\
\hline Thigh ..... & 87 & $"$ & $\cdots y^{2}$ & $"$ & $\begin{array}{l}500 \\
10 \cdot 5\end{array}$ &, & \\
\hline Leg & 27 & $"$ & & $"$ & $\begin{array}{r}193 \\
3.7\end{array}$ & $"$ & $\begin{array}{l}30.8 \\
00.0\end{array}$ \\
\hline Ankle-joint & 120 & " & & " & $\begin{array}{l}3.4 \\
5 \cdot 4\end{array}$ & $"$, & \\
\hline Foot, partial ... & 2 & $"$ & & $"$ & & ", & 10.9 \\
\hline Knee-joint & 40 & , & & $"$ & $16 \cdot 6$ & ", & 79 \\
\hline Both ankle-its. & 1 & $"$ & $\cdots$ & $"$ & 0 & ', & 333 \\
\hline Both feet & 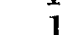 & ", & $\cdots$ & $" 2$ & 1000 & "n & \\
\hline Both forearms. & - & 3 & & 23 & & 93 & , \\
\hline Both legs ...... & 1 & $"$ & $\cdots$ & $"$ & $100 \cdot 0$ & 9 & 9 \\
\hline Elbow-joint ... & 1 & ", & $\ldots$ & , & & ", & \\
\hline Hand. & $\mathbf{1}$ & 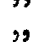 & $\ldots$ &, & & 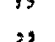 & 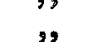 \\
\hline Total. & 32 & & &, & 8 & , & \\
\hline
\end{tabular}

Mortality of the Four Major Amputations for Disease.

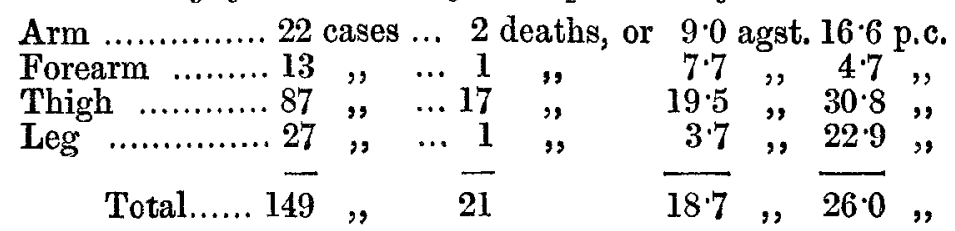

A decrease of $7 \cdot 3$ per cent. as compared with my previous statistics.

From the foregoing tables it will be observed that the diminished mortality is not an accidental circumstance, nor is it confined to any one division, but runs through them all to a greater or less degree. It is difficult to account for the diminution, as to all appearance the cases of injury were as severe as in former years, and the pbysique of those operated on for disease seemed neither better nor worse. Carbolic acid and other antiseptics were in almost general use ; but it is also of importance to state that during these eight years the heating of the wards was much improved by the introduction into them of hot-water pipes, keeping the temperature as nearly to $60^{\circ}$ as pos:ible.

I will now give in a tabular form the causes of death.

\section{Causes of Death.}

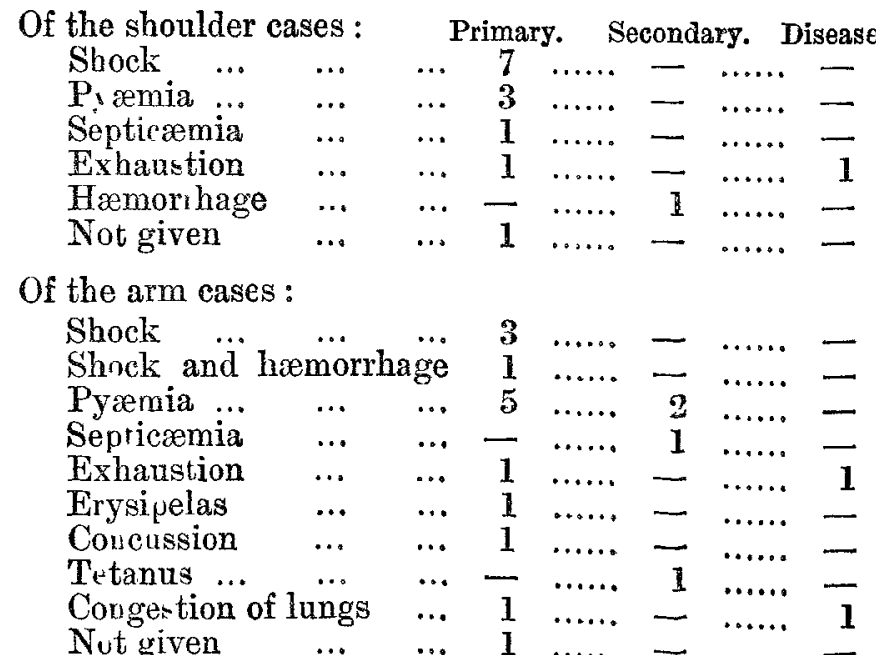

Of the forearm cases:

$\begin{array}{lllllllll}\text { Shock } & \ldots & \ldots & \ldots & \mathbf{1} & \ldots \ldots & \mathbf{1} & \ldots \ldots & - \\ \text { Pyærmia } \ldots & \ldots & \ldots & - & \ldots & \mathbf{2} & \ldots \ldots & \mathbf{1} \\ \text { Pertonitis } & \ldots & \ldots & \mathbf{1} & \ldots \ldots & - & \ldots \ldots & - \\ \text { On day of operation } & \ldots & - & \ldots \ldots & \mathbf{1} & \ldots \ldots & -\end{array}$

Of the hip.joint cases:

Shock

During operation

$$
\begin{array}{llllll}
\ldots & 1 & \ldots \ldots & -\ldots \ldots & 2 \\
\ldots & 1 & \ldots \ldots & -\ldots . .
\end{array}
$$

Of the thigh cases :

$\begin{array}{lllllllll}\text { Shock } & \ldots & \ldots & \ldots & 10 & \ldots \ldots & 3 & \ldots . . & 1\end{array}$

Shock and hæmorrhage $\quad \begin{aligned} & 1 \\ & \text { 1 }\end{aligned}$

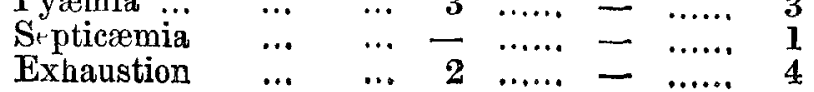

Tranmatic delirium ... Primary Secondary. Disease

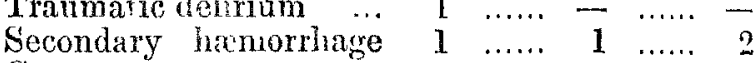

$\begin{array}{lllllllll}\text { Gangrene } & \ldots & \ldots & 1 & \ldots \ldots & 2 & \ldots \ldots & 1\end{array}$

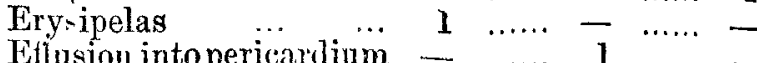

Eflusion intopericardiom $-\ldots . ., 1 \ldots .$.

Bronchitis and diarrhœa $-\ldots . . \quad$ - $\ldots .$.

Phthisis ... $\ldots . . \quad \ldots-\ldots \ldots-\ldots . .2$

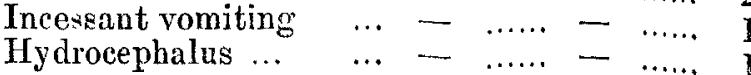

Of the leg cases:

Shock

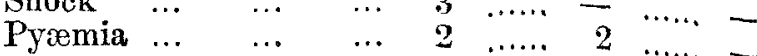

$\begin{array}{llllllll}\text { Gangrene } & \ldots & \ldots & 2 & \ldots \ldots & 2 & \ldots \ldots . & \\ & \ldots & \ldots & 2 & \ldots . . & 3 & \ldots . & -\end{array}$

$\begin{array}{llllllll}\text { Exhaustion } \quad \ldots & \ldots & 1 & \ldots . & 1 & \ldots . . . & -\end{array}$

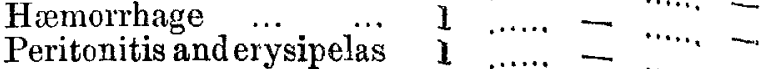

Peritonitis anderysipelas $1 \ldots . . . \quad \ldots . .$.

Albuminuria $\quad \ldots \quad \ldots=\overline{1} \ldots \ldots . \ldots, \ldots, 1$

Of ankle-joint :

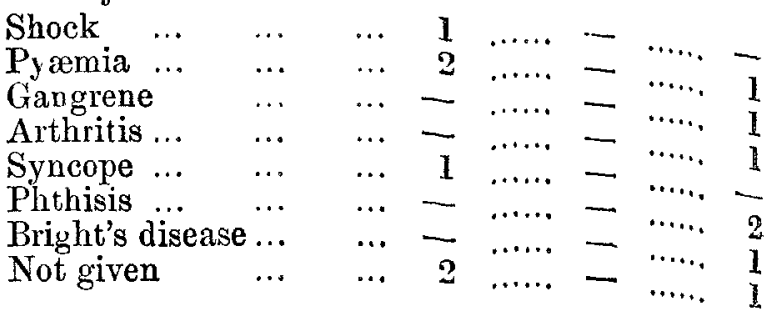

Of knee-joint:

Shock. $\ldots \quad \ldots \quad \ldots \quad 4 \quad \ldots . . \quad-\ldots .$.

Pyæmia $\ldots \quad \ldots \quad \ldots \quad 2 \ldots \ldots-\ldots .$.

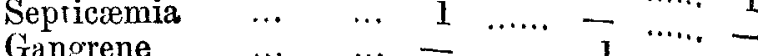

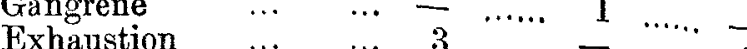

Secondary hæmorrhage $-\cdots \cdots . \cdots . . .2$

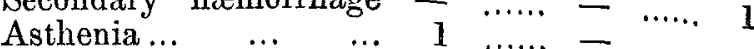

Loss of blood $\ldots \ldots, \ldots \quad 1 \quad \ldots \ldots-\cdots \cdots$

Traumatic meningitis ... $1 \ldots . . .-\ldots . .$.

Popliteal aneuriem $\quad \ldots-\ldots . .1 \quad 1 \ldots .$.

On day of operation $\ldots-\ldots . . \quad 1 \ldots . .$.

Not given $\quad \ldots \quad \ldots-\ldots . . \quad-\ldots . .3$

Of multiple cases :

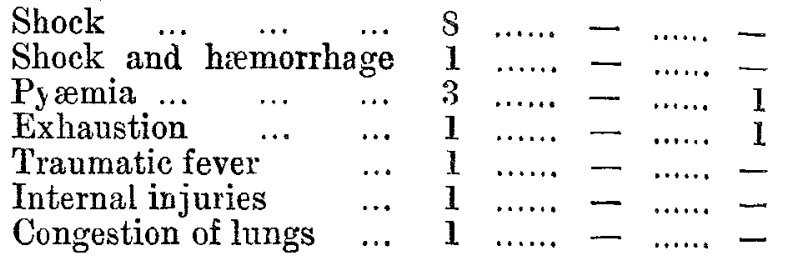

From January 1st, 1877, to December 31st, 1881, only 3 deaths from pyæmia and one from septicæmia are recorded. Of the total 165 deaths, 22 died on the day of operation, and 11 within forty-eight hours after being operated on. Deducting, then, 33 from the total number and from the deaths as being perfectly hopeless cases on admission, and on whom amputation was performed merely to make them comfortable, or in vague phraseology to give them a chance, the number of amputations will be 697 , the deaths 132 , and the mortality 18.9 per cent. No hospital patient who does not live three days after admission should be reckoned in the mortality statistics (although I have reckoned them even when they died on the operating table), for death occurring within that period indicates that the case was hopeless from the first. It is only beyond that period that nature and the skill of the surgeon can be called into play. To enable such cases to be excluded, I have since the year 1877 given in the operation table in my annual statistics the residence in hospital after each important operation when the patient dies; and I venture to recommend its adoption by hospital statisticians. Why should hospitals or operators be credited with deaths which were really the result of the severity of the injuries, and which it was impossible to combat? For several years I have taken the mortality of the wards, excluding those who died within forty-eight hours after admission, and the result in the surgical wards was an average mortality of 4 per cent. It gives a truer test of what can be accomplished than is done by the present system.

I intended to have given the expenditure per patient for surgical dressings and stimulants, but as the paper is already too long I will defer this to another occasion. 